\title{
Hydrogen Surface Coverage Dependence of the Reaction between Gaseous and Chemisorbed Hydrogen Atoms on a Silicon Surface
}

\author{
Jongbaik Ree, Kyung Soon Chang, ${ }^{\dagger}$ and Yoo Hang Kim ${ }^{\ddagger}$ \\ Department of Chemistry Education, Chonnam Kational Lniversity, Kwangu 500-757, Korea \\ Department of Chemistry, Chonnam National Cniversitw, Kwangiu 500-757, Korea

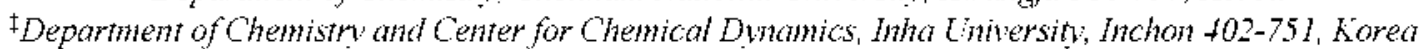 \\ Received October 9, 2001
}

\begin{abstract}
The reaction of gas-phase atomic hydrogen with hydrogen atoms chemisorbed on a silicon surface is studied by use of the classical trajectory approach. Especially. we have focused on the mechanism changes with the hydrogen surface coverage difference. On the sparsely covered surface. the gas atom interacts with the preadsorbed hydrogen atom and adjacent bare surface sites. In this case, it is shown that the chemisorption of $\mathrm{H}(\mathrm{g})$ is of major importance. Nearly all of the chemisorption events accompany the desorption of $\mathrm{H}(\mathrm{ad})$. i.e.. a displacement reaction. Although mich less important than the displacement reaction, the formation of $\mathrm{H}_{2}(\mathrm{~g})$ is the second most significant reaction pathway. At gas temperature of $1800 \mathrm{~K}$ and surface temperature of $300 \mathrm{~K}$. the probabilities of these two reactions are 0.750 and 0.065 , respectively: The adsorption of $\mathrm{H}(\mathrm{g})$ without dissociating $\mathrm{H}(\mathrm{ad})$ is found to be negligible. In the reaction pathway forming $\mathrm{H}_{2}$. most of the reaction energy is carried by $\mathrm{H}_{2}(\mathrm{~g})$. Although the majority of $\mathrm{H}_{-}(\mathrm{g})$ molecules are produced in sub-picosecond. direct-mode collisions. there is a small amount of $\mathrm{H}_{2}(\mathrm{~g})$ produced in multiple impact collisions, which is characteristic of complex-mode collisions. On the filly covered surface. it has been shown that the formation of $\mathrm{H}_{2}(\mathrm{~g})$ is of major importance. All reactive events occur on a subpicosecond scale. following the Eley-Rideal mechanism. At gas temperature of $1800 \mathrm{~K}$ and surface temperature of $300 \mathrm{~K}$, the probability of the $\mathrm{H}_{2}(\mathrm{~g})$ formation reaction is 0.082 . In this case. neither the gas atom trapping nor the displacement reaction has been found.
\end{abstract}

Keywords : Hydrogen. Silicon, Reactive desorption.

\section{Introduction}

In the reaction of gas-phase hydrogen atoms with chemisorbed hydrogen atoms on a silicon surface. the reaction pathway that has been recently investigated is the formation of $\mathrm{H}_{2}$ by an Eley-Rideal (ER) mechanism. In this gasadatom interaction. the reaction is initiated by the incidence of gas-phase atoms. which are initially not in equilibrium with the surface. and the reaction produces $\mathrm{H}_{2}$ on a subpicosecond time scale. There can be other reaction pathways. however. especially when bare silicon sites are available to incident gas atoms. They may even follow a LangmuirHinshelwood mechanism $(\mathrm{LH})^{2}$ or a mechanism that is intermediate between the ER and LH types. such as a hot precursor mechanism wherein gas atoms are trapped in the neighborhood of the surface but are not thennalized. ${ }^{3.4}$ Identifying various pathways and determining their branching ratios are important problents in understanding the mechanisms of this silicon-surface process. where the nature of the surface and interactions between the gas and surface atonis affect the outcone of the reaction. ${ }^{56}$

In this paper, we have focused on the change of the reaction pathways of gas-phase atomic hydrogen with the hydrogen atoms chemisorbed on a silicon $(001)-(2 \times 1)$ surface depending upon the change of the hydrogen surface

${ }^{*}$ Author to whom comespondence should be addressed. e-mail: jbreetchonnan.ac.kr coverage. The interaction model considered in Ref. $I$ is appropriate for the reaction of gas-phase atoms with adatoms in the case of high surface coverage, where the gassurface interaction is weak. In the case of sparsely covered surface in which $\mathrm{H}$ atoms are adsorbed at only a small portion of Si atoms, however. bare surface sites surrounding the $\mathrm{H}$-preadsorbed sites can also interact with the incident atom. thus opening up other reaction pathways in addition to the $\mathrm{H}_{2}$ formation channel. Thus, incident $\mathrm{H}(\mathrm{g})$ can adsorb. and becomes fully or partly equilibrated with the surface, and then further reacts with the preadsorbed $\mathrm{H}(\mathrm{ad})$ through a precursor mechanism or remains on the surface permanently. We shall study these possibilities and determine branching ratios of various competing reaction channels. In addition to the study of such reaction pathways. we also study the extent of the reaction exothemicity which is imparted to the product $\mathrm{H}_{2}$ molecule, as well as the energy that has dissipated into the bulk solid phase. The main part of the methodology is to follow the time evolution of the pertinent coordinates and conjugate momenta of each trajectory on a London-Eyring-Polanyi-Sato (LEPS) potential energy surface, which includes many-body interactions between all atoms of the system. The time evolution will be determined by solving the equations of motion formulated by uniting gassurface dynamics procedure and generalized Langevin theory for the solid phase. ${ }^{78}$ In addition to studying ensemble averages of the reaction events, we take representative trajectories of each reaction pathway to analyze the dyna- 
mics of bond dissociation and bond formation. We consider the reaction that takes place at gas temperature of $1800 \mathrm{~K}$ and surface temperature of $300 \mathrm{~K}$. The gas temperature of $1800 \mathrm{~K}$ used in the present calculation is known to be the typical experimental condition for producing hydrogen atoms."

\section{Interaction Model and Energies}

The interaction model and numerical procedures have already been reported in Ref. 1 . In this work we study the sparsely covered surface with bare sites and compare the results. when necessary. with those of the fully covered silicon surface reported in Ref. 1. We summarize the essential aspects of the interaction on the silicon $(001)-(2 \times 1)$ surface reconstructed by forming dimers along the [110] direction, Figure l(a). For easy reference we have displayed the collision model in Figure l(b). The $\mathrm{H}$ atom is chemisorbed on the $\mathrm{Si}$ aton of the symmetric dimer structure. This $\mathrm{Si}$ atom is the zeroth member of the $(N-1)$-atom chain which links the reaction zone to the heat bath, providing a quasi-physical picture of energy flow between the reaction zone and the chain atons and, in turn. between the chain and the heat bath. The motion of these chain atoms is an important part of the gas - surface interaction because it also describes a nonrigid surface. Furthermore, the zeroth Si atom is surrounded by eight nearby $\mathrm{Si}$ atonis of the symmetric dimer strands. ${ }^{10}$ These eight $\mathrm{Si}$ atonts surrounding $\mathrm{H}(\mathrm{ad})-\mathrm{Si}_{\mathrm{i}}$ are identified by numbers $1.2, \ldots .8$ in Figure 1(b). When there are bare Si sites. they interact with the incident $\mathrm{H}(\mathrm{g})$ gas atom through a strong chenisorption type energy. whereas the interaction between the gas atom and zeroth $\mathrm{Si}$ is a weak physisorption type. The reaction zone atoms are the zeroth $\mathrm{Si}$ atom, the adatom $\mathrm{H}(\mathrm{ad})$, and the incident $\mathrm{H}(\mathrm{g})$ gas atom. We consider that these reaction zone atoms, eight surrounding $\mathrm{Si}$ atonts. and the $N$-chain atoms constitute the primary system. We then designate the remaining infunite number of solid atons as secondary atoms. In the present model, we consider only one hydrogen atom on top of the zeroth $\mathrm{Si}$ atom. the state which has been shown to be of major importance over the dihydrogenated or trihydrogenated cases. ${ }^{\text {11.l: }}$

A total of six degrees of freedon is needed to describe the motions of $\mathrm{H}(\mathrm{g})$ and $\mathrm{H}(\mathrm{ad})$ atoms above the surface. Although it is straightforward to transform these coordinates to the center-of-mass and relative coordinate systems. we find it convenient to describe the collision system including surface atoms in terms of the atonic coordinates for the gas atom $\mathrm{H}\left(x_{\mathrm{H}}, y_{\mathrm{H}}, z_{\mathrm{H}}\right)$ and for the adatom $\mathrm{H}\left(x_{\mathrm{H}}^{\prime} \cdot y^{\prime}{ }_{\mathrm{H}}^{\prime} \cdot z_{\mathrm{H}}\right)$. For $\mathrm{H}(\mathrm{ad})$, they are $r_{\mathrm{siH}} \sin (\alpha+\theta) \cos \phi . r_{\mathrm{siH}} \sin (\alpha+\theta) \sin \phi$. and $r_{\mathrm{SiH}} \cos (\alpha+\theta)$, i.e. $\mathrm{H}\left(r_{\mathrm{SiH}}, \theta\right.$. $\left.\phi\right)$. where $r_{\mathrm{SiH}}$ is the adatom-to$\mathrm{Si}$ i distance. The angles $\theta$ and $\phi$ determine the orientation of the $\mathrm{H}(\mathrm{ad})-\mathrm{Si}_{\mathrm{j}}$ bond with respect to the surface normal and $x$-axis. respectively: see Figure 1 . Prior to dissociation the adatom tilted at an angle of $\alpha=20.6^{\circ 13}$ undergoes hindered motions along $\theta$ and $\phi$. For the position of $\mathrm{H}(\mathrm{g})$ with respect to the reference axis along the adatom. the $\mathrm{H}(\mathrm{g})-\mathrm{H}(\mathrm{ad})$ interatomic distance $r_{\mathrm{HH}}$ is $\left(\rho^{2}-z^{2}\right)^{1 / 2}$, where $\rho$ is the distance between $\mathrm{H}(\mathrm{g})$ and the $\mathrm{H}(\mathrm{ad})$ - surface normal axis, and $z$ is the vertical distance from $\mathrm{H}(\mathrm{g})$ to the horizontal line determining the position of $\mathrm{H}(\mathrm{ad})$. Note that the initial $(t \rightarrow-\infty)$ value of $\rho$ is the impact parameter $b$. The projection of $r_{\mathrm{HH}}$ on the surface plane is oriented by the angle $\Phi$ from the $X$ axis. Thus. the coordinates $\left(x_{\mathrm{H}}^{\prime}, y_{\mathrm{H}}^{\prime}, z_{\mathrm{H}}\right)$ can be transformed into the cylindrical system $(\rho, Z . \Phi)$ where $Z$ is the $\mathrm{H}(\mathrm{g})$-to-surface distance. The vertical distance $z$ is then $z=Z-r^{\prime} \mathrm{Hs} \cos (\alpha+\theta)$. The occurrence of each reactive event can be determined by studying the time evolution of the $\mathrm{H}(\mathrm{g})$ - surface distance $Z$. the $\mathrm{H}(\mathrm{ad})-\mathrm{Si}_{\mathrm{i}}$ bond distance $r_{\mathrm{HSj}}$. and the $\mathrm{H}(\mathrm{g})$-to-H(ad) distance $r_{\mathrm{HH}}\left(\rho^{2}+\right.$ $z^{12}$ for the ensemble of gas atoms approaching the surface from all directions. The initial state is chosen to be that of the gas atom approaching the surface with the collision energy $E$, impact parameter $b$. and azinuthal angle $\Phi$ from a large distance from the surface $(\approx 20 \AA)$, where the adatom is in the initial set of $\left(\mu_{\mathrm{HS},}, \theta, \phi\right)$.

Each reactive event can be described in terms of the interaction of $\mathrm{H}(\mathrm{g})$ with the adatom, nine surface atoms. and $N$ chain atoms. A rigorous form of the interaction potential

(a)
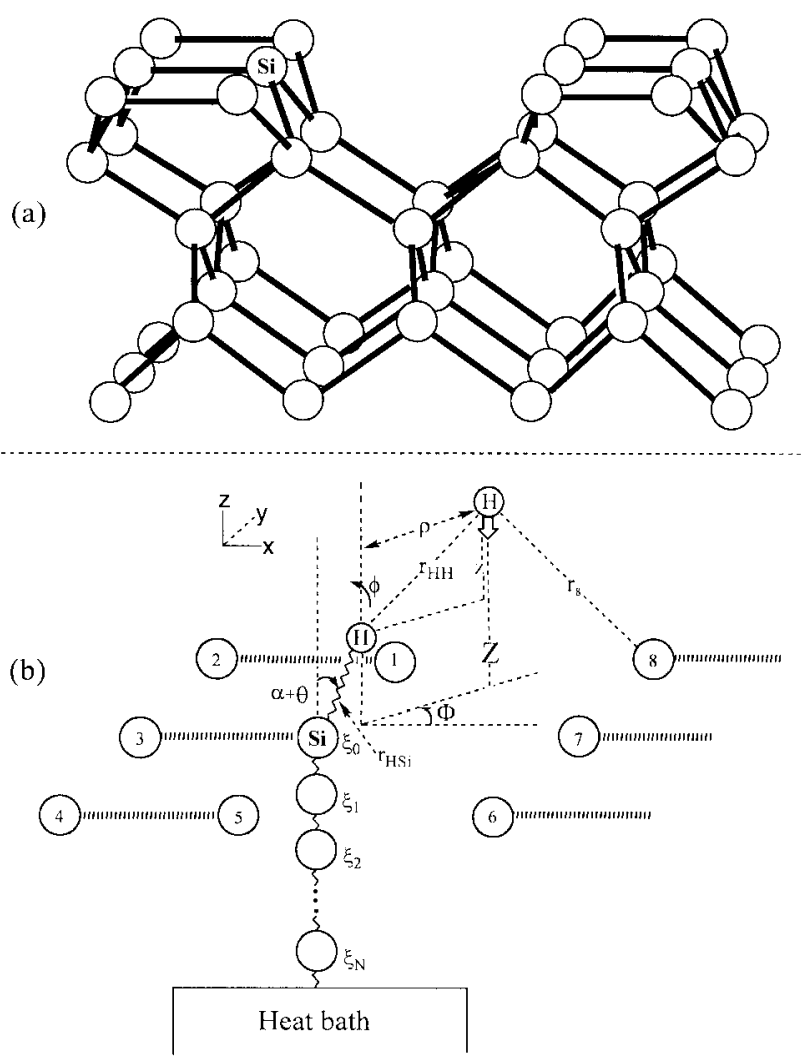

Figure 1. (a) Symmetric Si-Si dimer surface. (b) Interaction model showing the $\mathrm{H}(\mathrm{ad})$ atom adsorbed on the 0th $\mathrm{Si}$ atom. which is coupled to the $\mathrm{N}$-atom chain. The coordinates of the $(\mathrm{N}+\mathrm{I})$ chair atoms including the oth atom are denoted by $\xi_{0}, \xi_{1}, \cdots, \xi_{k}$. The 0 th atom is identified by $\mathrm{Si}$ in both (a) and (b). The Nth atom of the chain is coupled to the heat bath. The position of $\mathrm{H}(\mathrm{ad})$ is defined by $(r$ His, $\theta, \phi)$ and the position of $\mathrm{H}(\mathrm{g})$ by $(\rho, Z, \Phi) . \alpha$ is the tilt angle. The $\mathrm{H}(\mathrm{g})$ to $\mathrm{H}(\mathrm{ad})$ distance is denoted by $i_{\mathrm{HH}}$ and the $\mathrm{H}(\mathrm{g})$ to the $i$ th surface-layer $\mathrm{Si}$ atom distance by $r_{1}$. 
can be obtained including all these atom - atom interactions. We combine a modified form of the LEPS potential energy surface $^{1 j}$ for the interactions of $\mathrm{H}(\mathrm{g})$ to $\mathrm{H}(\mathrm{ad}) . \mathrm{H}(\mathrm{ad})$ to $\mathrm{Si}_{(\mathrm{i}}$. and $\mathrm{H}(\mathrm{g})$ to nine surface-layer atoms with the $\theta$ - and $\phi$ hindered rotational motions and the harmonic motions of the $(N+1)$-chain atoms to obtain the overall interaction energy:

$$
\begin{aligned}
& U=\left\{Q_{\mathrm{HH}}-Q_{\mathrm{HSl}}-Q_{\mathrm{HS}}-\left[A_{\mathrm{HH}}{ }^{2}-A_{\mathrm{HSl}}{ }^{2}-A_{\mathrm{HS}}{ }^{2}\right.\right. \\
& \left.\left.-A_{\mathrm{HH}} A_{\mathrm{HSl}}-\left(A_{\mathrm{HH}}-A_{\mathrm{HSl}}\right) A_{\mathrm{HSS}}\right]^{1:}\right\} \\
& +1 / 2 k_{\theta}\left(\theta-\theta_{k}\right)^{2}+1 / 2 k_{0}\left(\phi-\phi_{\ell}\right)^{2}+\sum_{y}\left(1 / 2 M_{s} \omega_{e j}{ }^{2} \xi_{i}^{2}\right) \\
& +\sum_{j} \text { (terms of type } M_{s} \omega_{i j}=\xi_{j-1} \xi_{1} \cdot M_{s} \omega_{c, j-1}=\xi_{j} \xi_{j-1} \text {, etc). }
\end{aligned}
$$

where $k_{\theta}$ and $k_{b}$ are force constants. $\theta_{e}$ and $\phi_{\varepsilon}$ are the equilibrium angles, $M_{\mathrm{s}}$ is the mass of the silicon atom. $\omega_{2 j}$ is the Einstein frequency. and $\omega_{i j}$ is the coupling frequency characterizing the chain. The explicit forms of the Coulomb terms $(Q$ ss) and exchange terms $(A ' s)$ for $\mathrm{HH}$. HSi. and HS are given in Ref. 1. In Equation (1), $Q_{\mathrm{HS}}$ and $A_{\mathrm{Hs}}$ each contains nine terms for the $\mathrm{H}(\mathrm{g})-\mathrm{Si}_{1}, \mathrm{H}(\mathrm{g})-\mathrm{Si}_{1} . \mathrm{H}(\mathrm{g})-\mathrm{Si}_{8}$ interactions. Since $r_{\mathrm{i}} \equiv r_{\mathrm{i}}\left(r_{\mathrm{HSi}} \quad \theta, \quad \phi . \quad \rho, \quad Z . \quad \Phi\right)$ and $r_{\mathrm{HH}} \equiv r_{\mathrm{HH}}\left(\mu_{\mathrm{HSj}}, \theta, \rho . Z\right)$, the potential energy surface has the functional dependence of $U\left(/_{\mathrm{HSi},}, \theta, \phi, \rho . Z . \Phi .\{\xi\}\right)$. where $\{\xi\}=\left(\xi, \xi_{1}, \cdots, \xi\right)$ for the vibrational coordinates of the $(N+1)$-chain atoms.

The potential and spectroscopic constants for the $\mathrm{H}(\mathrm{g})$ $\mathrm{H}(\mathrm{ad}), \mathrm{H}(\mathrm{ad})-\mathrm{Si}_{\mathrm{c}}$, and $\mathrm{H}(\mathrm{g})$ - surface interactions are $D_{0 . \mathrm{HH}}^{0}$ $=4.478 \mathrm{eV}_{0}^{14} D_{0 . \mathrm{HS}}^{0}=3.50 \mathrm{eV}^{15,16} D_{0 . \mathrm{HS}}^{0}=3.50 \mathrm{eV}^{1.1 .16}$ $\omega_{\mathrm{HH}} /(2 \pi \mathrm{c})=4401 \mathrm{~cm}^{-1}{ }^{1+}{ }^{1+}{ }_{\mathrm{H} \mathrm{S} /} /(2 \pi \mathrm{c})=2093 \mathrm{~cm}^{-1} \cdot{ }^{17.18}$ and $\omega_{\mathrm{H}} \mathrm{s} /(2 \pi \mathrm{c})=2093 \mathrm{~cm}^{-1} \cdot{ }^{17.18}$ The well-depth constants which enter in the Coulomb and exchange terms for $\mathrm{H}(\mathrm{g})-\mathrm{H}(\mathrm{ad})$. $\mathrm{H}(\mathrm{ad})-\mathrm{Si}_{\mathrm{i}}$ and $\mathrm{H}(\mathrm{g})$ - surface are determined as $D_{\mathrm{HH}}=$ $D_{0 . \mathrm{HH}}^{0}-1 / 2 \hbar \omega_{\mathrm{HH}} . D_{\mathrm{HSi}}=D_{0 . \mathrm{HS} 1}^{0}+1 / 2 \hbar \omega_{\mathrm{HSi}}$ and $D_{\mathrm{HS}}=$ $D_{0 . \mathrm{HS}}^{0}-1 / 2 \hbar \omega_{\mathrm{Hs}}$. respectively. The exponential range parameters which enter in these terms are determined from the relation $\sigma_{i}=\left(D_{i} / 2 \mu_{i}\right)^{1: 2} / \sigma_{\mathrm{j}}$ for $i=\mathrm{HH}, \mathrm{HSi}$, or HS. ${ }^{1(i)}$ The equilibrium distances of the $\mathrm{H}(\mathrm{g})-\mathrm{H}(\mathrm{ad}), \mathrm{H}(\mathrm{ad})-\mathrm{Si}_{j}$. and $\mathrm{H}(\mathrm{g})$ - surface bonds are $d_{\mathrm{HH}}=0.741 \AA^{1+} d_{\mathrm{HSj}}=1.514 \AA^{13}$ and $d_{\mathrm{HS}}=1.5 \mathrm{~L}+\AA^{13}{ }^{13}$ Now, it should be interesting to note that for the fully covered surface $\mathrm{H}(\mathrm{g})$-surface interaction is the physisorption type, but for the sparsely covered surface this interaction is chemisorption type except for the $\mathrm{H}(\mathrm{g})$ to zeroth $\mathrm{Si}$ interaction. For the $\mathrm{H}(\mathrm{g})$ to zeroth $\mathrm{Si}$ interaction. which is the physisorption type, we take $D_{\mathrm{Hs}}=0.0433 \mathrm{eV}$. $c_{\mathrm{HS}}=0.40 \AA$ and $d_{\mathrm{HS}}=3.38 \AA .{ }^{3}$ For the $x$ and $y$ directions. vibrational energies $\hbar \omega_{\mathrm{HSi} . \mathrm{r}}$ and $\hbar \omega_{\mathrm{HS}, \mathrm{y}}$ of the $\mathrm{H}(\mathrm{ad})$ atom chemisorbed on $\mathrm{Si}_{i j}$ are $645 \mathrm{~cm}^{-1}$, ${ }^{\text {is }}$ whereas the $z$-direction vibrational energy is $2093 \mathrm{~cm}^{-1} .17,1 \mathrm{~s}$

Each Coulonb and exchange tern of the LEPS potential function contains the Sato parameter $(\Delta)$. By varying values of $\Delta$ 's systematically. we find the set of Sato parameters best describing the desired features ninimizing barrier height and attractive well in the product chamel to be $\Delta_{\mathrm{HH}}=0.32$. $\Delta_{\mathrm{HSi}}=0.16, \Delta_{\mathrm{HS}}=0.15$ for the reaction zone $\mathrm{Si}$ atom (i.e. the $\mathrm{H}(\mathrm{g})$-to-zeroth $\mathrm{Si}$ atom $)$ and $\Delta_{\mathrm{HS}}=0.40$ for the $\mathrm{H}(\mathrm{g})$-toremaining eight surface-layer $\mathrm{Si}$ atoms. The barrier height on the resulting potential energy surface plotted for $\theta=\phi=$ $0^{\circ}$ and $b=0$ is $0.05 \mathrm{eV}$ or $1.2 \mathrm{kcal} / \mathrm{mol}$. For this reaction. the activation energy is known to be $\sim 1.0 \mathrm{kcal} / \mathrm{mol} .^{1.2 .21}$

Once the potential energy surface (PES) is determined, we can follow the time evolution of the primary system by integrating the equations. which describe the motions of the reaction-zone atoms and $N$-chain atoms on the surface. We expect that this PES will enable us to understand how gas atoms with given initial conditions react with chemisorbed atoms and then desorb from the surface. An intuitive way to treat the dynamics of the reaction involving many surface atoms is to solve a united set of equations of motion for the reaction-zone atoms and the Langevin equation for $N$-chain atoms, which couples the reaction zone to the heat bath. The gas - adatom part of the resulting equations are $m_{1} \ddot{Y}_{i}(t)=$ $-U / \partial Y$, where $Y_{1}=Z, Y_{2}=\rho . Y_{3}=\Phi, Y_{4}=r_{\mathrm{HSi}}, Y_{5}=\theta$, $Y_{6}=\phi$. with $\quad m_{1}=m_{\mathrm{H}}, \quad m_{2}=\mu_{\mathrm{HH}} . \quad m_{3}=I_{\mathrm{HH}} . \quad m_{4}=\mu_{\mathrm{HS}}$, $m_{s}=m_{6}=I_{\mathrm{HSj}}$. Here $\mu_{i}$ and $I_{i}$ are the reduced mass and the moment of inertia of the interaction system indicated. For the $(N+1)$-atom chain, which includes the zeroth $\mathrm{Si}$ atom, the equations are

$$
\begin{aligned}
& M_{s} \xi_{0}(t)=-M_{s} \omega_{e n}^{2} \xi_{0}(t)+M_{s} \omega_{c l}^{2} \xi_{1}(t) \\
& -\partial U\left(z_{\mathrm{HS},}, \theta, \phi . \rho, Z, \Phi,\{\xi\}\right) / \partial \xi_{i} \\
& M_{s} \ddot{\xi}_{i}(t)=-M_{s} \omega_{c j}^{2} \xi_{j}(t)+M_{s} \omega_{c i}^{2} \xi_{i-1}(t) \\
& +M_{s} \omega_{s, i-1}^{2} \xi_{j+1}(t) . \quad j=1,2, \ldots . N-1 \\
& M_{s} \ddot{\xi}_{N}(t)=-M_{s} \Omega_{N}^{2} \xi_{N}(t)+M_{s} \omega_{C . N}^{2} \xi_{V-1}(t) \\
& -M_{s} \beta_{N-1} \xi_{N}(t)+M_{s} f_{N-1}(t)
\end{aligned}
$$

Equation (2a) is for the vibration of the zeroth chain atom on which the $\mathrm{H}$ atom is chemisorbed. Equation (2c) is for the vibration of the $N$ th atom which is bound to the bulk phase. The Nth Si is directly linked to the heat bath. and through this coupling the heat bath exerts systematic dissipative and random (or stochastic) forces on the primary system composed of the reaction zone atoms and the $N$-chain atoms. $\Omega$ is the adiabatic frequency. The friction coefficient $\beta_{N^{-1}}$ is very close to $\pi \omega_{\nu} / 6$. where $\omega_{D}$ is the Debye frequency, and govents the dissipation of energy from the primary zone to the heat bath. All values of $\beta$, $\omega_{k}$. $\omega_{k}$. and $\Omega$ are presented elsewhere ${ }^{\wedge 2}$ The quantity $M_{s} f(t+1)$ is the random force on the primary system arising from thermal fluctuation in the heat bath. This force balances, on the average. the dissipative force, $M_{s} \beta_{\beta^{*}+1} \dot{\xi}_{*}(t)$. which removes energy from the $(N+1)$ atom chain system in order that the equilibrium distribution of energies in the chain can be restored after collision.

\section{Calculations and Discussion}

The computational procedures include an extensive use of Monte Carlo routines to generate random numbers for initial conditions. The first step of the procedures is to sample collision energies $E$ from a Maxwell distribution at the gas 
temperature $T_{z}$ and to weigh the initial energy of $\mathrm{H}(\mathrm{ad})-\mathrm{Si}_{\mathrm{c}}$ and all chain atom vibrations by a Boltzmann distribution at the surface temperature $T_{s}$. For the $\mathrm{H}(\mathrm{g})$-to- $\mathrm{H}(\mathrm{ad})$ interaction, the incident angle can be determined as $\theta_{\text {ist }}=\tan ^{-1}(\rho / z)$. whereas for each ith of nine surface $\mathrm{Si}$ atoms. it is $\cos ^{-1}(Z /$ $r_{i}$ ). Thus the incident angle for each atom continuously varies as the $\mathrm{H}(\mathrm{g})$ aton approaches the surface. In sampling impact parameters for the sparsely covered surface, we note that the horizontal distance between the equilibrium position of $\mathrm{H}(\mathrm{ad})$ and the surface normal axis through the third $\mathrm{Si}$ is $3.057 \AA$. The equilibrium dimer $\mathrm{Si}-\mathrm{Si}$ distance is 2.524 $\mathrm{A}^{13}$ This $\mathrm{Si}-\mathrm{Si}$ distance is much shorter than the distance between two adjacent dimers. which is $3.866 \AA^{13}$ The nearest $\mathrm{Si}-\mathrm{Si}$ distance between two different strands (e.g. zeroth and seventh) is $5.153 \AA^{1 \hat{3}}$ To include the $\mathrm{H}(\mathrm{g})$ atom approaching adjacent $\mathrm{Si}$ atoms from the outside (e.g.. $\mathrm{H}(\mathrm{g})$ approaching the third $\mathrm{Si}$ from the left-hand side), we add one-half of this $\mathrm{Si}-\mathrm{Si}$ distance $\mathrm{l} / 2 \times 5.153 \AA$ to $3.057 \AA$. That is. we take the flat sampling range of $0 \leq b \leq 5.633 \AA$ (i.e. $b_{\text {max }}=5.633 \AA$ ) for inpact parameters. This sampling scheme will enable us to treat all trajectories leading to the reaction of $\mathrm{H}(\mathrm{g})$ with adjacent bare sites for the sparsely covered surface. (Note that if the surface is fully covered. the sampling range is $0 \leq b \leq 1.80 \AA$ ) Also sampled are the initial values of $\theta, \phi$. and $\Phi$. Thus each trajectory starts out

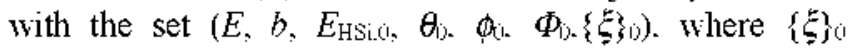
represents the initial values of $\{\xi\}=\left(\xi_{1 .} \xi_{1}, \ldots . \xi\right)$. We sample 60000 sets for each ensemble. The initial conditions and numerical techniques needed in solving the equations of motion are given in Ref. 10. Throughout this paper we have set the chain length of $(N+1)=10$ after checking the dependence of energy transfer to the solid as a function of $N$.

Reaction probabilities. We define the reaction probability $P_{i j}$ for reaction $(j)$ at gas and surface temperatures $\left(T_{g}, T_{s}\right)$ as the ratio of the number of reactive trajectories to the total number of trajectories sampled over the entire range of intpact parameters. At the thernal conditions of $\left(T_{\xi}, T_{s}\right)$ $(1800,300 \mathrm{~K})$. we fund the following three reactions occur on the sparsely covered surface:

$$
\begin{array}{lrl}
\mathrm{H}(\mathrm{g})+\mathrm{H}(\mathrm{ad}) / \mathrm{Si} \rightarrow \mathrm{H}_{2}(\mathrm{~g})+\mathrm{Si} . & P_{(1)}=0.065 \\
\mathrm{H}(\mathrm{g})+\mathrm{H}(\mathrm{ad}) / \mathrm{Si} \rightarrow \mathrm{H}(\mathrm{ad}) / \mathrm{Si}+\mathrm{H}(\mathrm{g}), & P_{(\mathrm{ul})}=0.750 . \\
\mathrm{H}(\mathrm{g})+\mathrm{H}(\mathrm{ad}) / \mathrm{Si} \rightarrow \mathrm{H}(\mathrm{ad}) / \mathrm{Si}+\mathrm{H}(\mathrm{ad}) / \mathrm{Si}, P_{(1,1)}=0.0002,
\end{array}
$$

(The sampling error is about $3 \%$. For example. $P_{[i \mathrm{j})}=0.065 \pm$ $0.0021)$ The chemisorption of $\mathrm{H}(\mathrm{g})$ is the most important reactive event. In this event, the disturbance of the H(ad) $\mathrm{Si}_{\mathrm{i}}$ bond by the adsorbing $\mathrm{H}(\mathrm{g})$ can be sufficiently strong such that it leads to the dissociation of the H(ad) - Sici bond. i.e.. displacement reaction represented by reaction (ii). Only a very small fraction of trajectories leads to the adsorption without dissociating the $\mathrm{H}(\mathrm{ad})-\mathrm{Si}$ bond (compare $P_{(\mathrm{iii})}=$ 0.0002 for this channel to $P_{(i i)}=0.750$ ). However. it should be interesting to note that there is no evidence of the gas atom trapping on the fully hy'drogen covered surface. ${ }^{.}$Such a large reaction probability for (ii) on the sparsely covered surface results from the strong interaction energy acting between $\mathrm{H}(\mathrm{g})$ and the bare surface sites. especially the third Si.

A smaller but significant fraction of the trajectories lead to $\mathrm{H}_{2}$ formation, the reaction probability being $P_{(j)}=0.065$. Thus. there are two major mechanisms that lead to the removal of preadsorbed $\mathrm{H}(\mathrm{ad})$ atoms on the sparsely hydrogen covered surface: reactions (i) and (ii). This result is in accordance with the experimental observation in the related system of $\mathrm{H}(\mathrm{g})$ interacting with $\mathrm{D}(\mathrm{ad}) / \mathrm{Si}$, where the primary pathways are found to be $\mathrm{H}(\mathrm{g})+\mathrm{D}(\mathrm{ad}) / \mathrm{Si} \rightarrow \mathrm{HD}(\mathrm{g})$ $+\mathrm{Si}$ and $\mathrm{H}(\mathrm{g})+\mathrm{D}(\mathrm{ad}) / \mathrm{Si} \rightarrow \mathrm{H}(\mathrm{ad}) / \mathrm{Si}+\mathrm{D}(\mathrm{g}) .^{21}$ As shown above, the $\mathrm{H}(\mathrm{g})$ adsorption process without dissociating the preadsorbed $\mathrm{H}(\mathrm{ad})$ atom. reaction (iii), is very inefficient. $\mathrm{A}$ similar result has already been noted by Kratzer for the trapping of hydrogen atoms in the $\mathrm{H}(\mathrm{g})+\mathrm{D}(\mathrm{ad}) / \mathrm{Si}$ and $\mathrm{D}(\mathrm{g})$ $+\mathrm{H}(\mathrm{ad}) / \mathrm{Si}$ systems. ${ }^{17}$ We also note that at the same thermal conditions of $(1800.300 \mathrm{~K})$. the probability of $\mathrm{H}_{2}$ formation in $\mathrm{H}(\mathrm{g})+\mathrm{H}(\mathrm{ad}) / \mathrm{Si}$ has been known to be $0.11,{ }^{11}$ which is not greatly different from our result.

In Ref. l. we have considered the interaction of $\mathrm{H}(\mathrm{g})$ with the preadsorbed $\mathrm{H}(\mathrm{ad})$. in which the $\mathrm{H}(\mathrm{g})$ - surface interaction is considered to be only the physisorption type and the sampling of impact parameters is carried out over $0 \leq b \leq$ $1.80 \AA$. Such interaction is appropriate for a fully covered surface. Here $b_{\max }=1.80 \AA$ is the halfway distance between the hydrogen atoms adsorbed on the nearest $\mathrm{Si}$ sites and the collision with $b>1.80 \AA$ represents the gas atom approaching the reaction zone of $\mathrm{H}(\mathrm{g})$ on the adjacent surface site. The probability of $\mathrm{H}_{2}$ formation calculated on the sparsely covered surface for $0 \leq b \leq 1.80 \AA$ at $(1800.300$ $\mathrm{K})$ is 0.208 . For the physisorption-type interaction over $0 \leq b$ $\leq 1.80 \AA$ on the fully covered surface considered in Ref. $I$ at (1800. $300 \mathrm{~K}$ ). the probability of $\mathrm{H}_{2}$ formation is 0.076 , which is much smaller than the value 0.208 of the sparsely covered surface over the same $b$ range. Therefore. one can see that the stronger the interaction between the incident $\mathrm{H}(\mathrm{g})$ atom and the surface $\mathrm{Si}$ atom becomes. the larger the probability of $\mathrm{H}_{2}$ formation is. The same trend has been reported in the case of $\mathrm{Cl}(\mathrm{g})+\mathrm{H}(\mathrm{ad}) / \mathrm{Si}$ sy stem. ${ }^{33}$

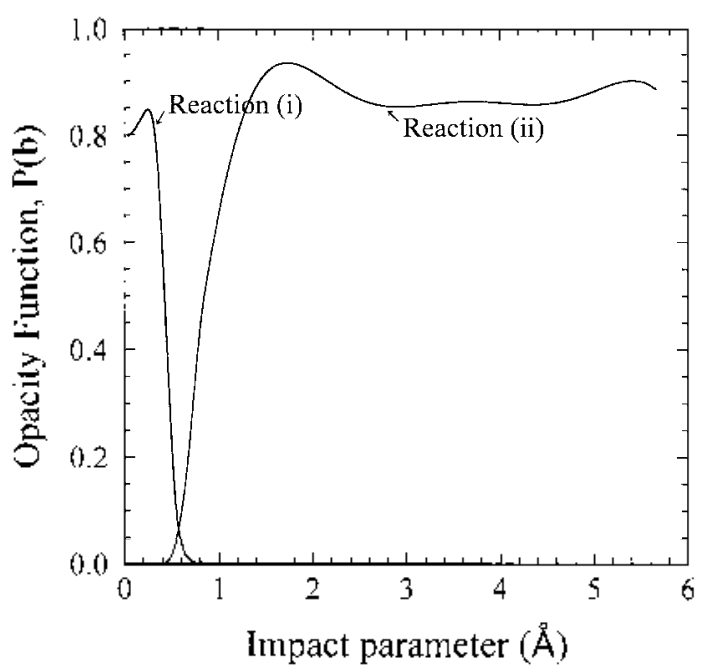

Figure 2. Dependence of the opacity function $P_{i i 1}(b)$ on the impact parameter for reactions (i) $\mathrm{H}_{2}$ formation; and (ii j, displacement. 
In order to examine this fact in detail, we plot the $b$ dependence of the opacity function $P_{i j:}(b)$ for the primary reaction pathways (i) and (ii) in Figure 2. As shown in Figure 2. $P_{0 \mathrm{i}}(b)$ is 0.80 in near $b=0$ collisions and rises to a maximum value of 0.85 near $b=0.3 \AA$. and then rapidly decreases to zero with increasing $b$. The production of $\mathrm{H}_{2}$ ceases for $b>0.8 \AA$. This indicates that reaction (i) is strongly localized in the neighborhood of the adatom site. The total reaction cross section calculated from the expression $\sigma=2 \pi \int_{0}^{b}{ }_{\max } P\left(T_{q}, T_{s ;} ; b\right) b d b$ for reaction (i) is as sinall as $0.305 \AA^{2}$. On the other hand. the opacity function $P_{i j i}(b)$ for displacement reaction is $\sim 0$ until about $b=0.4 \AA$ where $\mathrm{H}_{2}$ formation is very efficient. As shown in Figure 2. however. $P_{(i j)}(b)$ rises rapidly to near unity and remains there as the impact parameter increases toward its maximum value $b_{\text {max. }}$ where the probability of $\mathrm{H}_{2}$ formation is zero. The probabilities $P_{i \mathrm{ii}}(b)$ and $P_{(\mathrm{iij}}(b)$ vary in opposite directions as the intpact parameter increases. The appearance of large values of $P_{i \mathrm{iit}}(b)$ in a large $b$ collision is the result of $\mathrm{H}(\mathrm{g})$ adsorbing at one of the adjacent $\mathrm{Si}$ sites. The total cross section of this reaction is as large as $\sigma_{i \mathrm{iii}}=47.1 \AA^{2}$, which is close to the half of $\sigma_{\max }=\pi b_{\max }{ }^{2}=99.7 \AA^{2}$. The $b-$ dependent probabilities of reaction (iii) are very small and are not plotted in Figure 2. For this minor reaction channel. the total cross section is $\sigma_{i \mathrm{iij})}=0.005 \hat{\mathrm{A}}^{\mathrm{z}}$. We now discuss the details of each of these reaction pathways, with a greater emphasis on the $\mathrm{H}_{2}$ formation. reaction (i)

Reaction (i). The majority of reactive events following reaction (i) occur on a subpicosecond time scale, during which the adatom suffers only one impact with the surface. To determine this time scale. we first confinm the occurrence of a reactive event by following the motion of $\mathrm{H}(\mathrm{g})-\mathrm{H}(\mathrm{ad})$ for $50 \mathrm{ps}$. When $\mathrm{H}(\mathrm{g})-\mathrm{H}(\mathrm{ad})$ does not adsorb on the surface and is completely away from the influence of surface interaction, we trace the reactive trajectory backward to find the time at which the $\mathrm{H}(\mathrm{ad})$-to- $\mathrm{Si}_{\mathrm{j}}$ separation has reached $r_{\text {HSi.e }}+5.0 \AA$ where $r_{\text {HSi.e }}$ is the equilibrium distance of the $\mathrm{H}(\mathrm{ad})-\mathrm{Si}_{\mathrm{i}}$ bond $(1.514 \AA)$. We define the period from the start of collision to the time at which the $\mathrm{H}(\mathrm{ad})-\mathrm{Si}_{\mathrm{ij}}$ distance reaches $\left(r_{\mathrm{HSi}, e}+5.0\right) \AA$ as the reaction time $t_{R}$ for reaction (i). The ensemble-averaged reaction time is $0.083 \mathrm{ps}$ (See Figure 3(a)). This value is significantly smaller than that of the fully covered surface, 0.22 ps. (See Figures $3(a)$ and 3(b).) The subpicosecond time scale iniplies that the reaction is direct. In such a direct-mode collision. acceleration of the incident atom occurs both before and after impact. For the sparsely covered surface there is a bare Si site which strongly interacts with the incident gas atom, thus the acceleration is greater than for the fully covered surface. Therefore. the reaction time for the sparsely covered surface is much shorter than the fully covered surface.

We now consider the distribution of ensemble-averaged energies in the product state and compare the result with that of the fully covered surface ${ }^{\mathrm{l}}$ at $(1800.300 \mathrm{~K})$ in Table 1 . Listed are the ensemble-averaged translational, vibrational, and rotational energies of $\mathrm{H}_{-}(\mathrm{g})$ as well as the energy dissipated into the solid phase $\left\langle E_{s}\right\rangle$. In reaction (i) most of

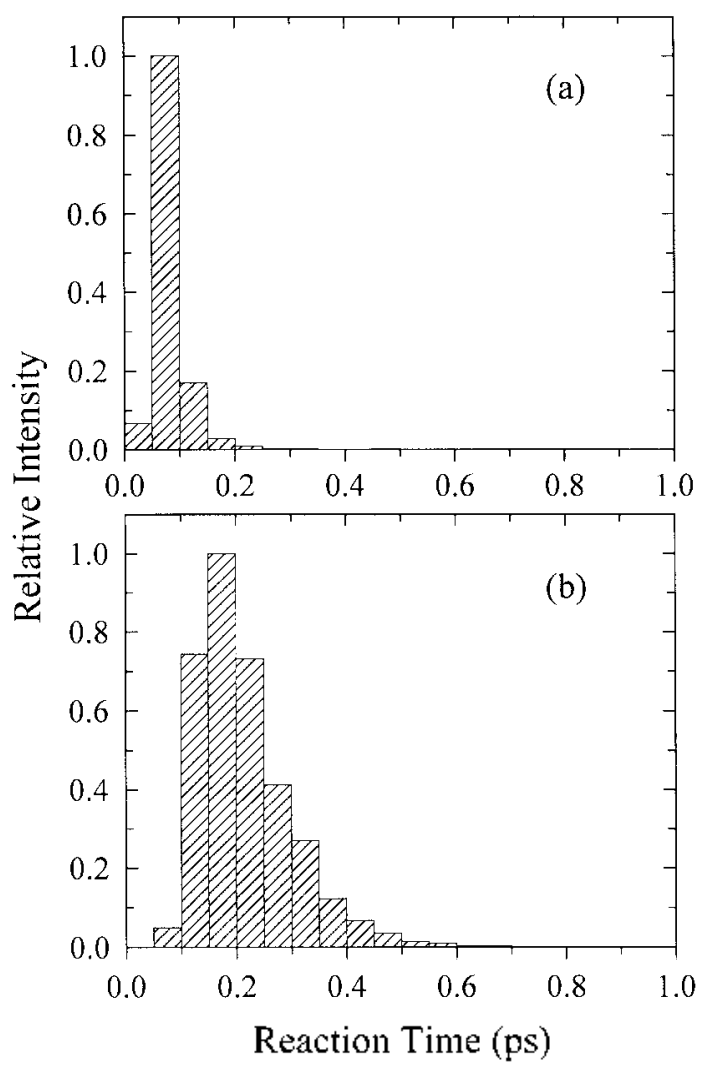

Figure 3. Reaction time distribution for reaction (i). (a) For the sparsely covered surface. (b) For the fully covered surface.

the reaction exothermicity deposits in the translational and vibrational motions of the product $\mathrm{H}_{2}$ molecule $(0.553$ and $0.662 \mathrm{eV}$, or $42.0 \%$ and $50.3 \%$, respectively). Energy is also partitioned to some extent into rotation, but the distribution indicates that the rotational motion is much less effective in promoting $\mathrm{H}_{2}$ formation. Into the bulk solid. $0.092 \mathrm{eV}$. or $7.0 \%$ of the available energy deposits. This energy disposal is different from that of the fully covered surface case, ${ }^{1}$ also shown in Table 1 for comparison. In the fully covered surface case, energy is carried away mostly by vibration. The vibrational energy accounts for nearly $62.3 \%$ of the available energy. Only $16.5 \%$ and $10.0 \%$ of the available energy deposit in translation and rotation. respectively. But, it is interesting to note that $\left\langle E_{\text {rot }}\right\rangle$ is significantly small in both cases. As mentioned above. in a direct-mode collision, acceleration of the incident atom occurs both before and after impact. Since the acceleration experienced by the incident atom on the sparsely covered surface is greater than on the fully covered surface, the energy deposited into the translational motion of the product $\mathrm{H}_{2}$ molecule is larger for

Table 1. Ensemble-averaged product energy distribution for reaction (i). Energies are in $\mathrm{eV}$

\begin{tabular}{lcccc}
\hline & $\left\langle E_{\text {tais }}\right\rangle$ & $\left\langle E_{\text {vob }}\right\rangle$ & $\left\langle E_{\text {rop }}\right\rangle$ & $\left\langle E_{\mathrm{s}}\right\rangle$ \\
\hline Sparsely covered $^{\prime \prime}$ & 0.553 & 0.662 & 0.011 & 0.092 \\
Fully covered $^{t}$ & 0.195 & 0.735 & 0.118 & 0.131 \\
\hline
\end{tabular}

${ }^{a}$ Present result. ${ }^{\circ}$ Taken from Ref. 1. 
the former surface that the latter surface. However, for both the sparsely and the fully covered surfaces, the $\mathrm{H}_{2}$ formation reaction occurs only in the localized neighborhood around the $\mathrm{H}$ adatom. Therefore. the torque experienced by the $\mathrm{H}_{2}$ molecule as it forms is relatively small, and this. in turn. imparts only a small anount of rotational energy to the desorbing molecule. The energy dissipated into the bulk solid, $\left\langle E_{\mathrm{s}}\right\rangle$, is nearly the same for both surfaces since the incident atom and adatom are the same. On the other hand. when the incident atom and the adatom are different. $\left\langle E_{\mathrm{s}}\right\rangle$ is quite different too. For example, in $\mathrm{H}(\mathrm{g})+\mathrm{Cl}(\mathrm{ad}) / \mathrm{Si}$ and $\mathrm{Cl}(\mathrm{g})+\mathrm{H}(\mathrm{ad}) / \mathrm{Si}$ collision dynamics, $\left\langle E_{\mathrm{s}}\right\rangle$ for the former is nearly twice that for the latter.

The vibrational energy distribution of $\mathrm{H}_{2}$ produced in reaction (i) is shown in Figure 4(a). The population is small for low vibrational energy and then increases to maximum value between 0.6 and $0.7 \mathrm{eV}$ before decreasing exponentially as the energy becomes higher. For the fully covered surface shown in Figure 4(b). the population is also small for low vibrational energy but its maximum appears at much higher energy, near $1.1 \mathrm{eV}$. Thus, the ensemble-averaged vibrational energy for the fully covered surface is larger than that for the sparsely covered surface.

In reaction (i) the rotational energy is calculated as $E_{\text {cot }}=$ $L^{2} /\left(2 \mu_{\mathrm{HH}^{\prime}}{ }_{\mathrm{HH}}{ }^{2}\right)$, where the angular momentum $L=\mu_{\mathrm{HH}}(z \dot{\rho}-$ $\rho \dot{j})$ with the corresponding quantum number $J=L / \hbar$. We use a binning procedure of assigning rotational quantum number $J_{\mathrm{HH}}$ corresponding to the calculated rotational energy $E_{\text {rot }}$ through the relation $J_{\mathrm{HH}}=\operatorname{int}\left[E_{\text {rot }} / E_{\text {rot }}\left(J_{\mathrm{HH}}\right)\right]$. where

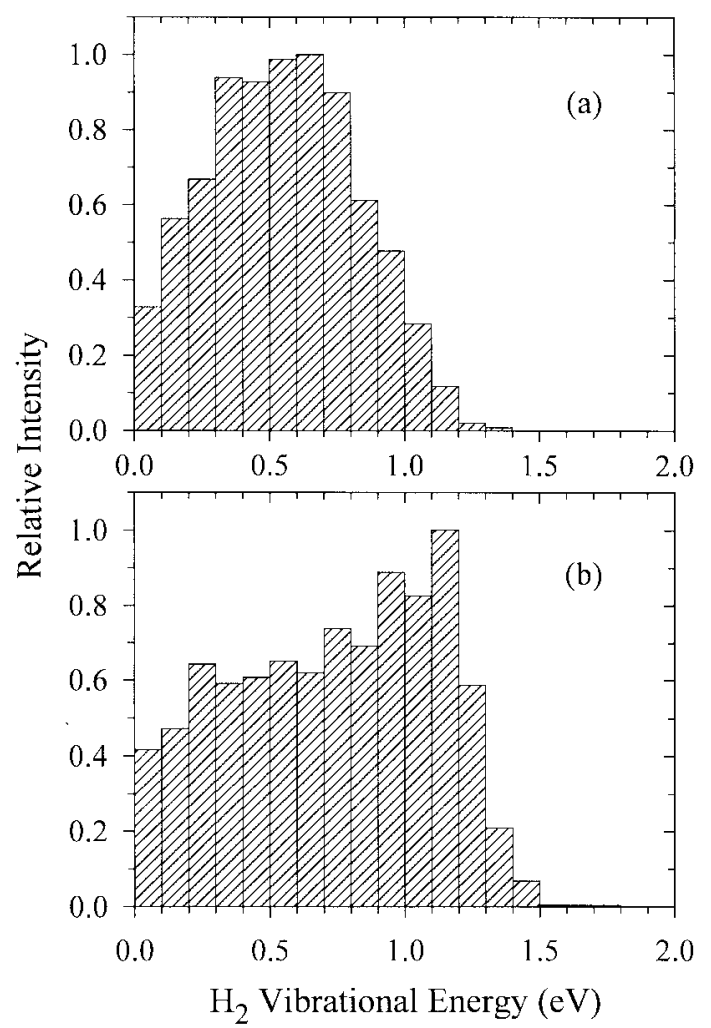

Figure 4. Vibrational energy distribution of $\mathrm{H}_{2}$ in reaction (i). (a) For the sparsely covered surface. (b) For the fully covered surface.
$E_{\mathrm{rot}}\left(J_{\mathrm{HH}}\right)=J_{\mathrm{HH}}\left(J_{\mathrm{HH}}+1\right) \hbar^{2} /\left(2 J_{\mathrm{HH}}\right)$. The maximum occurs at $J_{\text {max }}=0$ [see Figure 5(a)]. If we take the gas temperature of $1800 \mathrm{~K}$. the rotational maximum obtained from the Boltzmann expression $J_{\mathrm{max}}=1 / 2\left[(2 k T / \bar{B})^{1:-1}-1\right]$ with $\bar{B}=60.84$ $\mathrm{cm}^{-1}$ is 3 . On the other hand, for surface temperature of 300 $\mathrm{K}$, the Boltzmann intensity is sharply peaked at $J_{\max }=1$. The shape and intensity distribution of the calculated rotational states for the sparsely covered surface suggests that the rotational energy of product $\mathrm{H}_{2}$ is very small. For the fully covered surface too, the rotational energy shows the similar population. [See Figure 5(b).] As mentioned above. the energy deposited into the rotational motion of the $\mathrm{H}_{2}$ molecule formed on both sparsely and fully covered silicon surfaces is small.

The ensemble-averaged translational energy of $\mathrm{H}_{2}$ produced in reaction (i) is as large as $0.553 \mathrm{eV}$ for the sparsely covered surface, and we now look into the velocity distribution of these molecules. Figure 6 (a) shows a time-offlight distribution of $\mathrm{H}_{2}$ product molecules along with the fitted curve. The points are obtained by collecting molecules reacling the "reaction chamber-to-detector" distance of 30 $\mathrm{cm}$. The distribution of most points fits well with a velocity function of the form ${ }^{2-4} f(v)=A v^{2} e^{-i t-\tau_{11} 1^{2}: \alpha^{2}}$ with $A=1.02 \times$ $10^{-1 i}, v_{k i}=7207 \mathrm{~m} / \mathrm{s}$ and $\alpha=2598 \mathrm{~m} / \mathrm{s}$. This distribution is on a short-time scale with the maximum near $40 \mu \mathrm{s}$, and it represents direct-mode collisions taking place on a

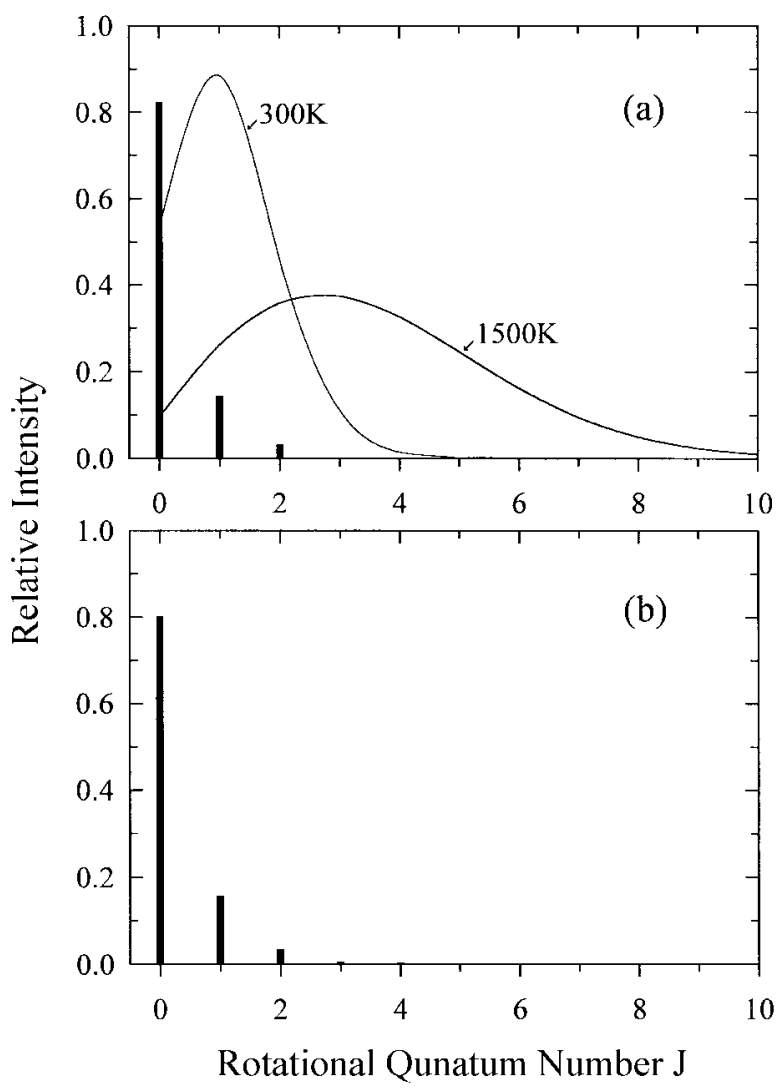

Figure 5. Relative intensity of the rotational population distribution of $\mathrm{H}_{2}$ in reaction (i). (a) For the sparsely covered surface (b) For the fully covered surface. 

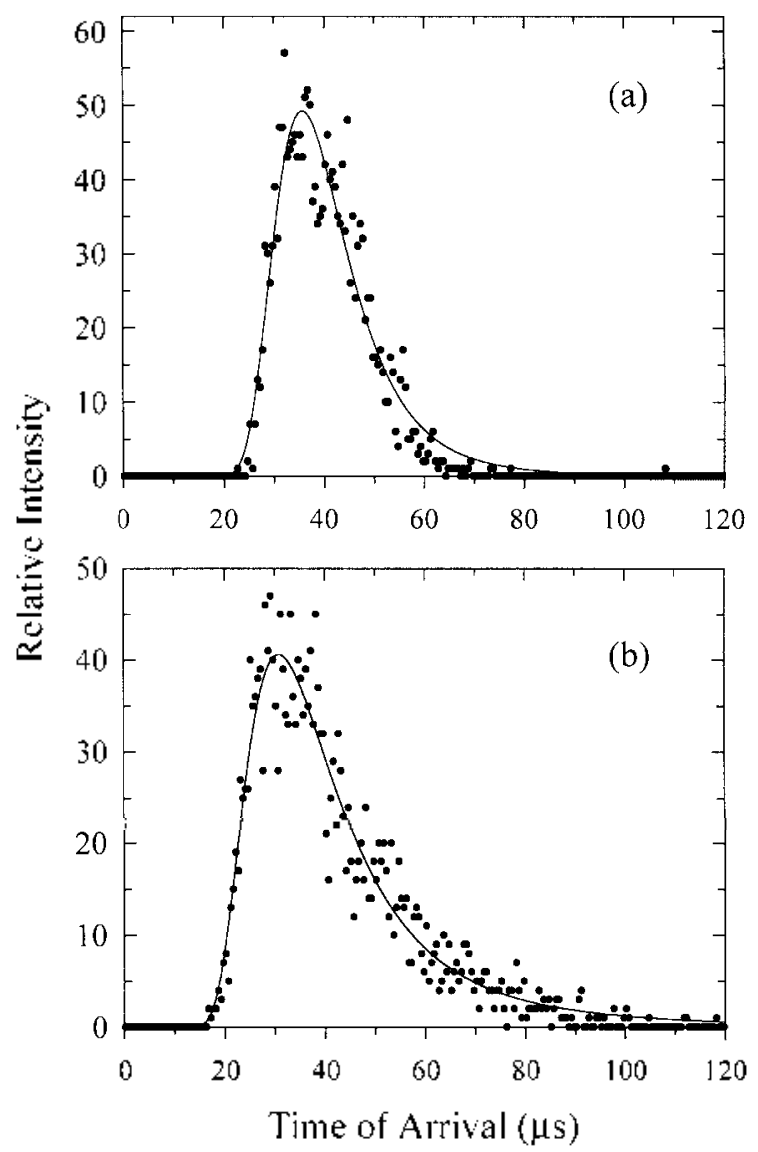

Figure 6. Time-of-flight distribution for $\mathrm{H}_{2}$ leaving from the surface in the reaction (i). (a) For the sparsely covered surface. (b) For the fully covered surface.

subpicosecond time scale. The velocity distribution takes the maximum value at $v_{\text {tax }}=1 / 2\left[v_{i}+\left(v_{i j}{ }^{2}+6 \hat{c}\right)^{1: 2}\right]=8+11 \mathrm{~m} / \mathrm{s}$. which gives $1 / 2 m_{\mathrm{HH}} v_{\max }{ }^{2}=0.739 \mathrm{eV}$. This energy is significantly large compared to $3 / 2 k T_{g}=0.233 \mathrm{eV}$, indicating that the velocity distribution is highly non-Boltznann. We also note that this energy is far in excess of $k T_{s}=0.026 \mathrm{eV}$. For the fully covered surface a time-of-flight distribution of $\mathrm{H}_{2}$ product molecules along with the fitted curve shown in Figure $6(\mathrm{~b})$ is broader than the sparsely covered surface. which can be expected from the reaction time distribution (See Figure 3). The ensemble averaged translational energy of the $\mathrm{H}_{2}$ molecules formed on the fully covered surface is smaller than that on the sparsely covered surface. Therefore. the velocity of the $\mathrm{H}_{\Sigma}$ molecule leaving the fully covered surface becomes slower and the time-of-flight distribution becomes broader.

We select a trajectory which is representative of this direct-mode collisions and plot the time evolution of its gas atom-surface distance $Z$, adatom - surface distance $\mu_{\mathrm{HSi}}$, and the $\mathrm{H}(\mathrm{g})-\mathrm{to}-\mathrm{H}(\mathrm{ad})$ distance $r_{\mathrm{HH}}$ in Figure 7 . The reaction time of this representative case is $0.105 \mathrm{ps}$. The time evolution of $\mathrm{H}(\mathrm{g})-\mathrm{H}(\mathrm{ad})$ and $\mathrm{H}(\mathrm{ad})-\mathrm{Si}_{\mathrm{i} j}$ vibrational energies is shown in Figure 7(b). The oscillation of the outgoing $/_{\mathrm{HSi}}$ is due to the rotation of $\mathrm{H}(\mathrm{g})-\mathrm{H}(\mathrm{ad})$ bond. In the present representative collision, the product molecule deposits 0.344

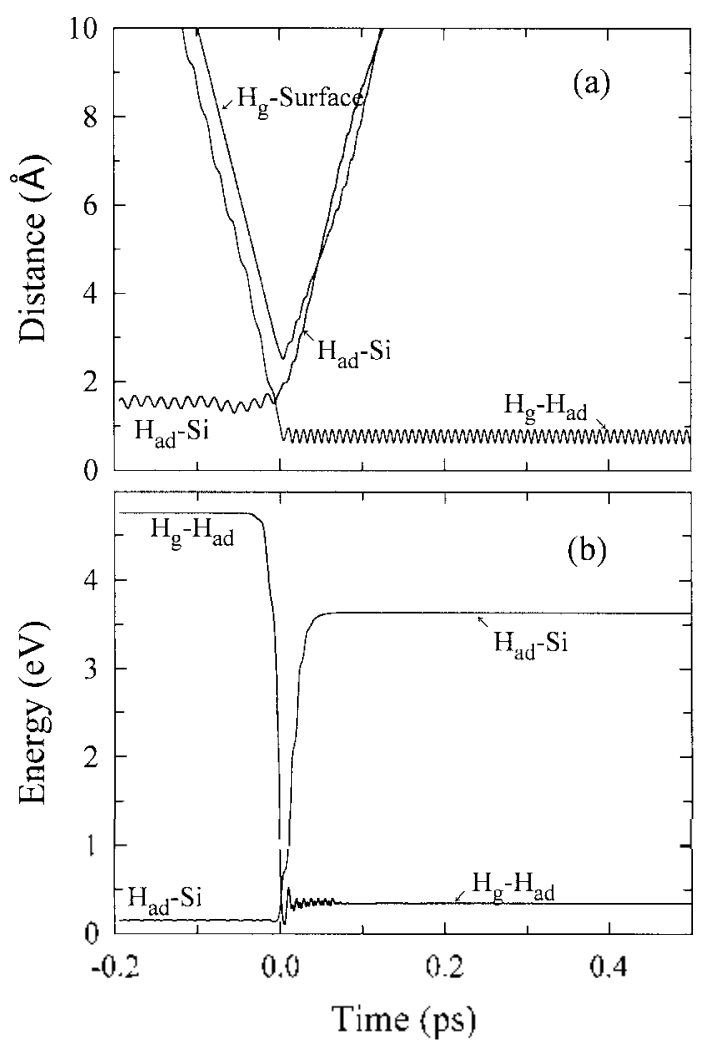

Figure 7. Dynamics of the representative trajectory for a directmode collision in reaction (i). (a) Time evolution of the $\mathrm{H}(\mathrm{g})$ to surface, $\mathrm{H}(\mathrm{ad})-\mathrm{Si}_{\mathrm{n}}$, and $\mathrm{H}(\mathrm{g})-\mathrm{H}(\mathrm{ad})$ distances. (b) Time evolution of the $\mathrm{H}(\mathrm{g})$ to $\mathrm{H}(\mathrm{ad})$ interaction energy and the $\mathrm{H}(\mathrm{ad})-\mathrm{Si}_{0}$ vibrational energy.

$\mathrm{eV}$ in its vibrational motion. Beyond $t=+0.07$ ps. the $\mathrm{H}(\mathrm{g})-\mathrm{H}(\mathrm{ad})$ vibrational energy stabilizes to a constant value of $0.344 \mathrm{eV}$ [Figure 7(b)] which occupies a large portion of the liberated energy. From the well-organized motion of the $\mathrm{H}(\mathrm{g})-\mathrm{H}(\mathrm{ad})$ vibration right after the tuming point [Figure 7(a)], the molecule appears to gain its gas phase properties while it is relatively close to the surface.

For the sparsely covered case, even though the number is significantly small compared with that of short-time events (or direct collisions), there are other types of collisions representing an important class of gas - surface reactions. They are trapping-mediated reactions. occurring in an indirect or complex-mode collision. In this type of collisions, the product molecule have had a sufficient time to acconmodate. at least partially, to the surface, and then leave the surface with a temperature close to $T_{s}$. For the fully covered surface, such collisions are not found. In Figure 8. we show the time evolution of a representative trajectory of such complex-mode collisions. The $\mathrm{H}(\mathrm{g})$-to-surface interaction begins near $t=-0.08 \mathrm{ps}$. and the incident $\mathrm{H}(\mathrm{g})$ atom suffers the first impact with the surface near $t=+0.02 \mathrm{ps}$. At this time, the $\mathrm{H}(\mathrm{g})$ atom comes in close range of the adatom causing a significant disturbance in the $\mathrm{H}(\mathrm{ad})-\mathrm{Si}_{\mathrm{ij}}$ interaction. As shown in Figure 8(a). the trapped $\mathrm{H}(\mathrm{g})$ atom rebounds, spending a relatively long time near the apex, where the kinetic energy vanishes. This is a barely trapped 


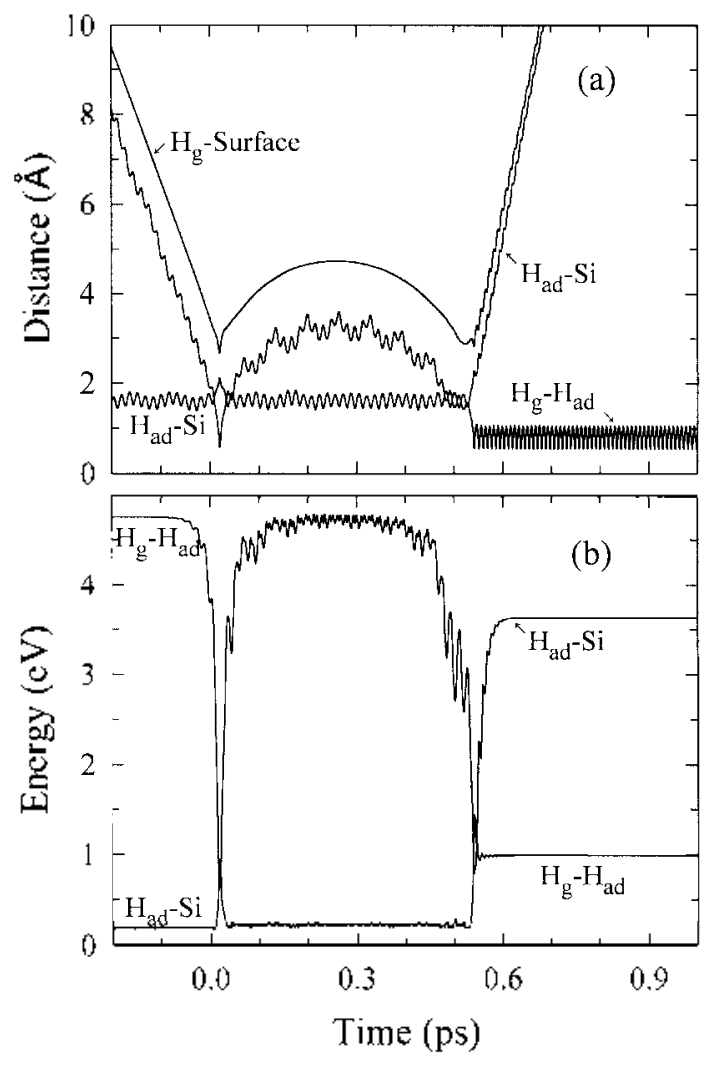

Figure 8. Dynamics of the representative trajectory for a complexmode collision in reaction (i). (a) Time evolution of the $\mathrm{H}(\mathrm{g})$ to surface, $\mathrm{H}(\mathrm{ad})-\mathrm{Si}_{0}$, and $\mathrm{H}(\mathrm{g})-\mathrm{H}(\mathrm{ad})$ distances. (b) Time evolution of the $\mathrm{H}(\mathrm{g})$ to $\mathrm{H}$ (ad) interaction energy and the $\mathrm{H}(\mathrm{ad})-\mathrm{Sin}$ vibrational energy.

trajectory. but the $\mathrm{H}(\mathrm{g})$ atom fails to escape, thus forming a loosely bound complex on the surface, $\mathrm{H}(\mathrm{g})-\mathrm{H}(\mathrm{ad})-\mathrm{Si}$. A fine structure of the $\mathrm{H}(\mathrm{g})-\mathrm{H}(\mathrm{ad})$ distance during the large amplitude oscillation is due to the $\mathrm{H}(\mathrm{ad})-\mathrm{Si}$ vibration. After completing the oscillation, the $\mathrm{H}(\mathrm{g})$ atom is attracted back to the surface for another impact near $t=0.55 \mathrm{ps}$, at which time $\mathrm{H}(\mathrm{g})$ abstracts $\mathrm{H}(\mathrm{ad})$ and turns around to move away from the surface. As shown in Figure 8(b). there is a rapid flow of energy from the $\mathrm{H}(\mathrm{g})-\mathrm{H}(\mathrm{ad})$ bond to $\mathrm{H}(\mathrm{ad})-$ $\mathrm{Si}_{\mathrm{i}}$ bond in the $\mathrm{H}(\mathrm{g})-\mathrm{H}(\mathrm{ad})-\mathrm{Si}_{\mathrm{i}}$ complex at the second impact. Until that time, the $\mathrm{H}(\mathrm{ad})-\mathrm{Si}_{i j}$ bond has remained essentially at the original bonding state, even though there has been a disturbance at the first impact. We note that during the large oscillation of the $\mathrm{H}(\mathrm{g})$ - surface distance between $t=-0.02$ and $+0.55 \mathrm{ps}$, the $\mathrm{H}(\mathrm{g})$-to- $\mathrm{H}(\mathrm{ad})$ energy is very close to that of the initial value of $D_{\mathrm{HH}}=4.75 \mathrm{eV}$. However, after the second impact, most of this energy is used to dissociate the $\mathrm{H}(\mathrm{ad})-\mathrm{Si}_{\mathrm{i}}$ bond, leaving the rest for the various modes of the final state. The buildup of $\mathrm{H}(\mathrm{ad})-$ $\mathrm{Si}_{\mathrm{i} i}$ vibrational energy toward the dissociation threshold $D_{\mathrm{HSi}}=3.63 \mathrm{eV}$ occurs on a time scale of about $0.1 \mathrm{ps}$ immediately following the final impact. It appears therefore that the decision as to whether there is sufficient energy for $\mathrm{H}(\mathrm{ad})$ - $\mathrm{Si}_{\mathrm{i}}$ dissociation is not made until a very late stage in the lifetime of $\mathrm{H}(\mathrm{g})$ on the surface. The receding molecule reaches a distance of $6 \AA$ at $t=-0.62 \mathrm{ps}$ with a vibrational
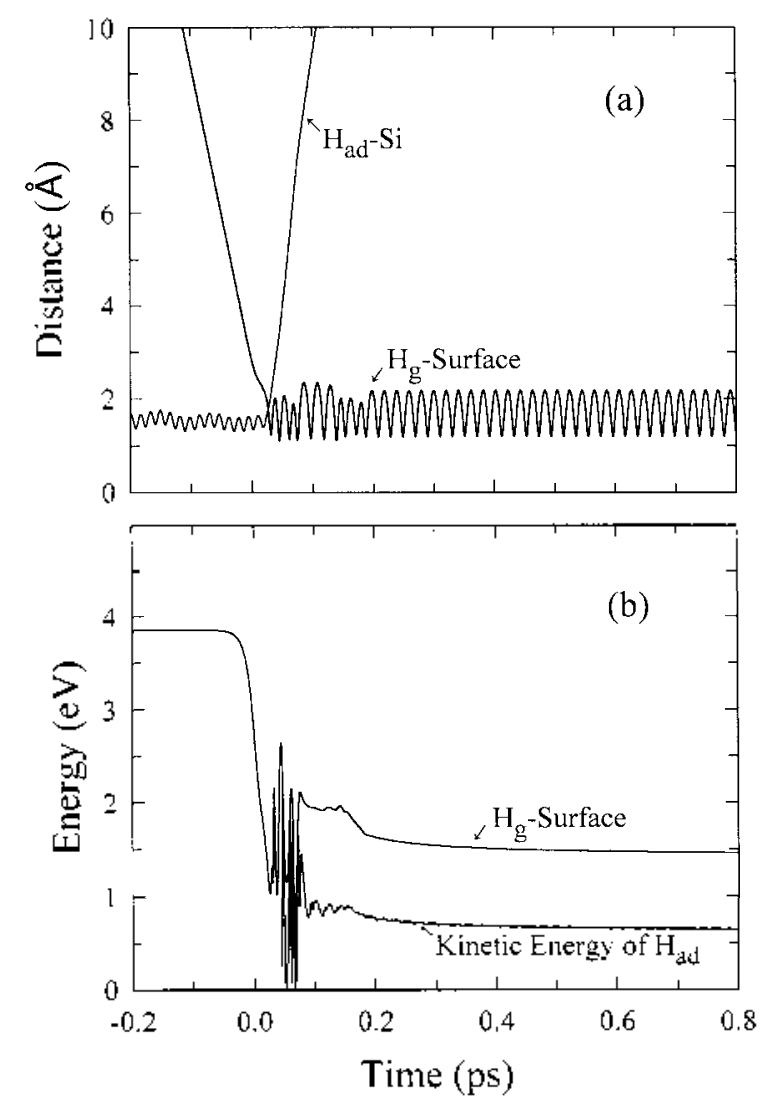

Figure 9. Dynamics of the representative trajectory for reaction (ii). (a) Time evolution of the $\mathrm{H}(\mathrm{g})$ to surface and $\mathrm{H}(\mathrm{ad})-\mathrm{Sio}$ distances. (b) Time evolution of the $\mathrm{H}(\mathrm{g})$-surface interaction energy and the kinetic energy of desorbing $\mathrm{H}$ (ad).

energy $0.987 \mathrm{eV}$. We regard this event to follow a precursortype mechanism. ${ }^{3,4}$

Reaction (ii). The probability of this displacement reaction is the largest of the three pathways revealed in the sparsely covered surface. As mentioned above. this reaction (ii) is not found in the fully covered surface. The $\mathrm{H}(\mathrm{g})$ atom interacts strongly with bare $\mathrm{Si}$ sites surrounding the zeroth atom in large impact parameter collisions. Thus, this reactive event can occur when $\mathrm{H}(\mathrm{g})$ adsorbs on one of the adjacent bare sites. As shown in Figure 2, large- $b$ collisions favor this reaction pathway. whereas collisions with a small value of $b$ favor reaction (i).

In Figure 9(a) we show the time evolution of the $\mathrm{H}(\mathrm{g})$ surface and $\mathrm{H}(\mathrm{ad})-\mathrm{Si}_{i j}$ distances for a trajectory representing events occurring through the concerted mechanism, in which the turning point nearly coincides with the $\mathrm{H}(\mathrm{ad})-\mathrm{Si}_{\mathrm{i}}$ dissociation. Most of the $\mathrm{H}(\mathrm{g})$-to-surface interaction energy deposits in the newly formed $\mathrm{H}(\mathrm{g})$ - Si vibration after dissociating the $\mathrm{H}(\mathrm{ad})-\mathrm{Si}_{\mathrm{i}}$ bond. The amount of energy deposited in the newly formed $\mathrm{H}(\mathrm{g})-\mathrm{Si}$ bond in this representative case is $1.457 \mathrm{eV}$. The rest is either carried away by the $\mathrm{H}(\mathrm{ad})$ atom as its kinetic energy or dissipated into the solid. These two energies are 0.645 and $0.109 \mathrm{eV}$. respectively [see Figure $9(\mathrm{~b})]$. The fast-moving $\mathrm{H}(\mathrm{ad})$ atom begins its outward joumey at $t=-0.023 \mathrm{ps}$. while an adjustment of the $\mathrm{H}(\mathrm{g})-$ 
surface vibrational motion is under way.

In reaction (ii). the ensemble average of energies deposited in the $\mathrm{H}(\mathrm{g})$ - surface vibration $\left\langle E_{\mathrm{vib}, \mathrm{H}(\mathrm{g} ; \mathrm{si}}\right\rangle$ is 1.387 $\mathrm{eV}$, thereby sharing the major portion of the liberated energy. whereas that of the kinetic energy carried away by dissociat-

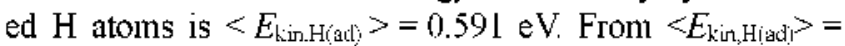
$3 / 2 \mathrm{kT}$. we find $T=4572 \mathrm{~K}$. suggesting the atoms produced are in a hot atom gas state. Since $D_{0, \mathrm{Hsi}}^{\prime}=3.50 \mathrm{eV}$. such a large value of $\left\langle E_{\mathrm{vib}, \mathrm{HSi}}\right\rangle$ represents the production of a $\mathrm{H}(\mathrm{g})$ - surface bond in a lighly vibrationally excited state in most adsorption events. The ensemble-averaged anount of energy propagated into the solid phase is $0.105 \mathrm{eV}$, which is very small compared with $\left\langle E_{\text {vib.Higi.si }}\right\rangle$ or $\left\langle E_{\text {kir }, H(a d)}\right\rangle$. Note that this value is very close to $0.083 \mathrm{eV}$ of reaction (i).

Reaction (iii). The reaction probability $P_{\text {(iii }}$ calculated at $(1800,300 \mathrm{~K})$ is only 0.0002 . For the fully covered surface. however. reaction (iii) is not found. This reaction starts out the same as reaction (ii) but ends with no desorption of the preadsorbed $\mathrm{H}(\mathrm{ad})$ atom. This $\mathrm{H}(\mathrm{g})$ adsorption process occurs when the incident gas atom interacts with both the adatom and the surface. In this case, the $\mathrm{H}(\mathrm{g})$ atom interacts with the adaton to form a weak $\mathrm{H}(\mathrm{g})-\mathrm{H}(\mathrm{ad})$ bond and the interaction is not strong enough to break the $\mathrm{H}$ (ad) $-\mathrm{Si}_{\mathrm{i}}$ bond. Although the number of reactive trajectories for this pathway is very sniall, the reaction is dominated by snuall $b$ collisions. in which the $\mathrm{H}(\mathrm{g})$ atom is incident more or less on top of the preadsorbed atom. The low-frequency oscillation of the $\mathrm{H}(\mathrm{g})$ - surface distance shown in Figure 10(a) clearly indicates that the $\mathrm{H}(\mathrm{g})$ atom is undergoing weak interaction with the surface.

For several representative trajectories of this reaction, we have followed the $\mathrm{H}(\mathrm{g})$ - surface distance for $50 \mathrm{ps}$ but found no evidence of dissociation; the adsorbed $\mathrm{H}(\mathrm{g})$ becomes fully equilibrated on the surface. Furthernore, the time evolution of the $\mathrm{H}(\mathrm{g})$ - surface distance at such a long time with a well-organized low frequency oscillation indicates that $\mathrm{H}(\mathrm{g})$ dissociation at sone later time is unlikely. The desorption would be possible if the $\mathrm{H}(\mathrm{g})$ atom interacts with a large amount of collision energy. but such a collision would lead to reaction (i), and reaction (iii) is dominated by low- $E$ collisions. The time evolution plotted in Figure 10(a) shows the $\mathrm{H}(\mathrm{g})-\mathrm{H}(\mathrm{ad})$ distance undergoing a low-frequency oscillation corresponding to the $\mathrm{H}(\mathrm{g})$-surface motion. because $\mathrm{H}(\mathrm{g})$ is bound to both $\mathrm{H}(\mathrm{ad})$ and the surface in this representative case. The power spectrum of the $\mathrm{H}(\mathrm{g})-\mathrm{H}(\mathrm{ad})$ vibration does not show a peak corresponding to the $\mathrm{H}_{2}$ frequency of $4400 \mathrm{~cm}^{-1}$ [see Figure 10(b)]. Instead. it shows sharp peaks at 2041 and $509 \mathrm{~cm}^{-1}$. which are the frequencies of the $\mathrm{H}(\mathrm{ad})-\mathrm{Si}_{\mathrm{i}}$ vibration and the hindered motion of adatom $\mathrm{H}(\mathrm{ad})$ along the $\theta$ - direction. The $\mathrm{H}(\mathrm{ad})-\mathrm{Si}$ bond executes a well-organized high-frequency vibration since $\mathrm{H}(\mathrm{ad})$ is still tightly bound to the surface. The high intensity peak at $2041 \mathrm{~cm}^{-1}$ shown in Figure 10(c) represents this vibration. This peak also appears in the $\mathrm{H}(\mathrm{g})-\mathrm{H}(\mathrm{ad})$ spectrum, because $\mathrm{H}(\mathrm{ad})$ is bound to the surface. thus imprinting the $\mathrm{H}(\mathrm{ad})-\mathrm{Si}_{\mathrm{i}}$ vibration in the $\mathrm{H}(\mathrm{g})-\mathrm{H}(\mathrm{ad})$ motion. Therefore, reaction (iii) does not represent the formation of
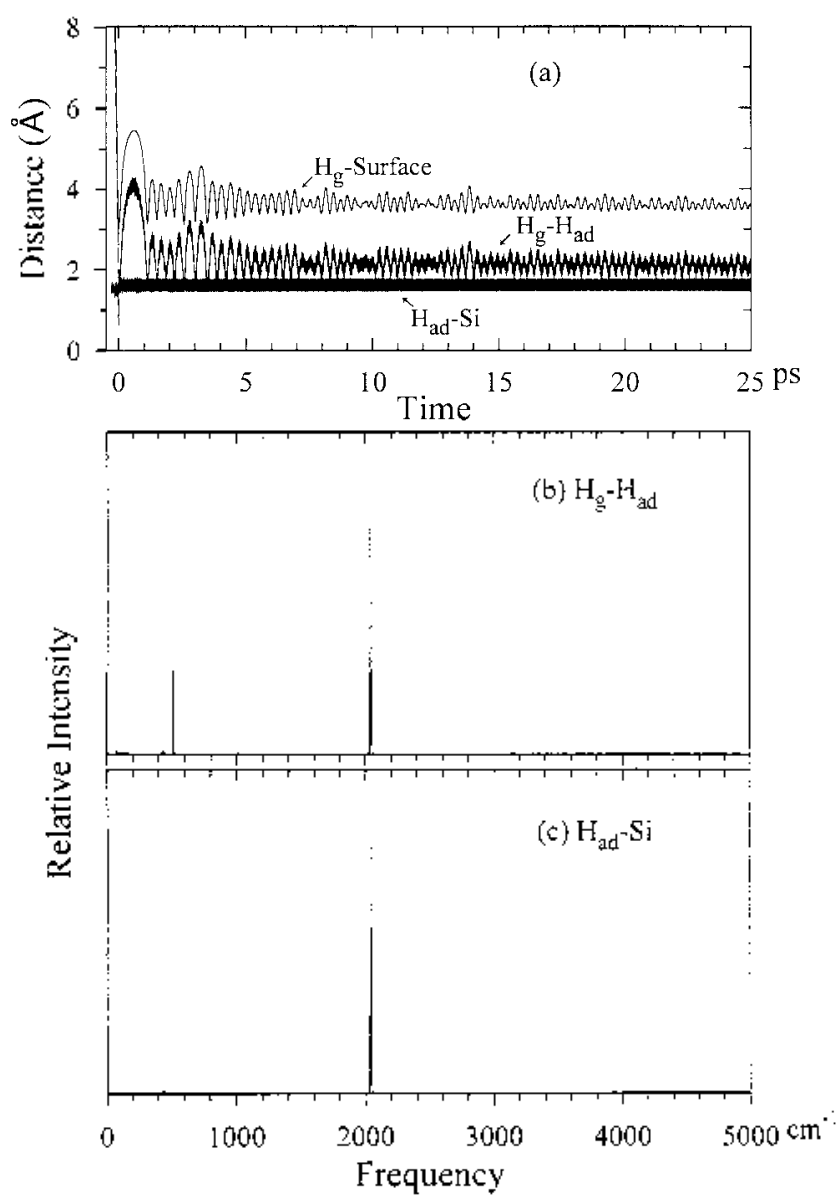

Figure 10. (a) Time evolution of the $\mathrm{H}(\mathrm{g})$ to surface, $\mathrm{H}(\mathrm{g})-\mathrm{H}(\mathrm{ad})$ and $\mathrm{H}(\mathrm{ad})-\mathrm{Si}_{\triangleleft}$ distances for a representative collision in reaction (iii). (b) Power spectrum of the $\mathrm{H}(\mathrm{g})-\mathrm{H}(\mathrm{ad})$ vibration. (c) Power spectrum of the $\mathrm{H}(\mathrm{ad})-\mathrm{Si}_{0}$ vibration.

trapped $\mathrm{H}_{2}$ on the surface.

\section{Concluding Comments}

The principal conclusion that can be drawn from this study on the collision of gas-phase atomic hydrogen with a silicon surface sparsely covered by hydrogen atoms is that there appear to be three reaction pathways. while the reaction pathway for the fully covered surface is only the formation of $\mathrm{H}_{2}(\mathrm{~g})$. For the sparsely covered surface, the primary pathways are the chemisorption of $\mathrm{H}(\mathrm{g})$ and the formation of $\mathrm{H}_{2}(\mathrm{~g})$. In the former reaction. the chemisorption of $\mathrm{H}(\mathrm{g})$ almost always leads to desorption of the preadsorbed $\mathrm{H}(\mathrm{ad})$ atom, a displacement reaction. Thus. these two reaction pathways are responsible for the removal of preadsorbed $\mathrm{H}(\mathrm{ad})$ atoms. The study predicts that large impact parameter collisions favor the displacement reaction, whereas collisions with a small impact parameter favor $\mathrm{H}_{2}$ formation. The pathway of chemisorption of $\mathrm{H}(\mathrm{g})$ atoms without dissociating the $\mathrm{H}(\mathrm{ad})$ - surface bond is found to be of minor importance. In the displacement reaction. the $\mathrm{H}(\mathrm{g})-\mathrm{Si}$ vibration removes most of the reaction exothemicity. but the energy slared by the desorbing $\mathrm{H}(\mathrm{ad})$ atom is significant. In $\mathrm{H}_{2}$ 
formation. most of the reaction energy deposits in the vibrational and translational motions of $\mathrm{H}_{2}$. In all reaction pathways, the amount of energy transfer to the solid phase is significant. Most of these reactive events occur through a direct-mode collision. However, in $\mathrm{H}_{2}$ formation reactions. a snall but siguificant number of reactive events occur through a complex-mode collision. Such reactive events can be regarded to follow a precursor-type mechanism. in which the trapped $\mathrm{H}(\mathrm{g})$ atom has sufficient time to acconmodate to the surface.

Acknowledgment. We wish to dedicate this paper to Professor Kyung Hoon Chung in Korea Advanced Institute of Science and Teclunology who has pioneered the gas dynamics research in Korea. The contputational part of this research was supported by "2nd Superconputing Application Support Progran" of the KISTI (Korea Institute of Science and Technology Infornation). J. R. gratefully acknowledges the financial support by Korea Research Foundation Grant (KRF-2000-015-DP0210)

\section{References}

1. Lim. S. H. Ree. I.; Kim. Y. H. Bull. Norem Chem Soc. 1999. 20. 1136.

2. Weinberg. W. H. In Dymamics of Gas-Surface Imeractions: Rettner. C. T.: Ashfold. M. N. R. Eds.: Royal Society of Chemistry: 1991: pp 171-219.
3. Harris. J.: Kasemo. B. Suf. Sci. 1981. 105, L281.

4. Harris. I.: Kasemo. B.: Törnqqist. E. Sinf. Sci. 1981. 105. L288.

5. Waltenburg. H. N.: Yates. T. T. Tr. Chent. Re? 1995. 95.1589

6. Doren. D. J. Adh Chem. Phys. 1996. 95. 1.

7. Adelman. S. A. J. Chem. Pins. 1979, 71. 4471.

8. Tully. J. C. J. Chem. Phus. 1980, 73. 1975.

9. Struve. W. S: Krenos. J. R.: MeFadden, D. L.: Herschbach. D. R. d. Chent. Phos 1975. 62.404

10. Kim. Y. H.: Ree. J.: Shin. H. K. J. Chent. Phns 1998. 108. 9821.

11. Koleske. D. D.: Gates. S. M.: Tackson. B. J. Chent. Phys. 1994. 101.3301

12. Gates. S. M.: Kunz, R. R.; Greenlief, C. M. Surf. Sci. 1989, 207. 364.

13. Radeke. M. R.: Carter. E. A. Phws. Rev: B 1996. 54. 11803.

14. Huber. K. P.: Herzberg. G. Contants of Diatontic Holectles: Van Nostrand Reinhold: 1979: pp 250)-251.

15. Van de Walle. C. G.; Street. R. A. Phws. Rev B 1995, 51 , 10615.

16. Kratzer. P; Hammer. B.; Norskov. J. K. Phys. Rev B 1995. 5 I. 13432

17. Kratzer. P. J. Chent. Phlss. 1997. 106.6752

18. Tully. I. C.: Chabal. Y. T.: Raghavachari. K.: Bowman. J. M.: Lucchese. R. R. Phns Rev $B$ 1985. 31.1184

19. Koleske. D. D.: Gates, S. M.: Schultz, J. A. J. Chem. Phus. 1993. 99. 5619.

20. Koleske. D. D.; Gates, S. M.: Jackson, N. J. Chem. Phus. 1994. 101.3301

21. Buntin. S. A. J. Chem. Phys. 1996. 105. 2066.

22. Ree. J.: Kim. Y. H.: Shin. H. K. J. Chent. PIns 1996. J04. 742.

23. Ree J.; Shin, H. K. J. Chem. Plns. 1999. 111. 10261.

24. Mullins. C. B.: Rettner. C. T.: Auerbach. D. J. J. Chem. Phys. 1991. 95,8649 